“I don’t see myself as a forty-year-old on Facebook”: Medical students’

dilemmas in developing professionalism with social media

Accepted for publication in the Journal of Further and Higher Education 24 March 2017

Fiona Curtis ${ }^{\mathrm{a}}$ and Julia Gillen ${ }^{\mathrm{b}}$

${ }^{a}$ Lancaster Medical School, Faculty of Health and Medicine, Furness College, Lancaster

University, Lancaster, United Kingdom, LA1 4YG. f.curtis@lancaster.ac.uk Tel: +44

(0)1524 594825

b Department of Linguistics and English Language, Faculty of Arts and Social Sciences, County South, Lancaster University, Lancaster, United Kingdom, LA1 4YL.

j.gillen@lancaster.ac.uk Tel: +44 (0)1524 510830

Corresponding author: Dr Julia Gillen, Department of Linguistics and English Language, Lancaster University LA1 4YL +44 (0)1524 510830. j.gillen@lancaster.ac.uk.

\title{
Acknowledge ments
}

The authors thank Joanne Thistlethwaite and Sten Hansson for research assistance.

\begin{abstract}
Students' development of professionalism is vital within medical education, while social media communications can blur professional and personal boundaries. In the UK considerable advice for medical practitioners and students has been developed, advocating care in the projection of a professional identity online as offline. This guidance includes the duty to raise matters of concern when encountered online. This study takes an academic
\end{abstract}


literacies approach to a small-scale investigation of attitudes and practices of second year medical students in a British university through a focus group and paired interview, recognising that issues of identity and power are multi-layered and complex.

Students' interactive use of social media focusses primarily on Facebook, where they had already begun to adapt their self presentation. Depictions of alcohol use are a particular area

of concern. Use of Facebook is seen as unavoidable in professional and personal domains. Students' reflections demonstrate professionalism in respect of care for patient confidentiality and privacy online as offline. Yet they express an ambivalent sense of a future trajectory in which continuing social media use may appear simultaneously undesirable and yet vital. A finding of considerable concern is a reluctance to challenge inappropriate online behaviour despite policy guidelines. Overall the findings of the study support conceptions of online and offline identities as entwined. New generations growing up with social media raise challenges and opportunities for medical education that require greater attention and the development of participatory approaches to research, increasing understandings that in turn may be beneficial for policy makers.

\section{Introduction: medical professionalism}

Doctors are required by their governing body, the General Medical Council GMC (GMC, 2013b), and expected by society (Chandratilake, McAleer, Gibson, and Roff 2010; Chretien and Kind 2014; Cruess, Johnston and Cruess R. 2004) including patients, to act in a professional manner. They must 'make sure that [their] conduct justifies [their] patients' trust in [them] and the public's trust in the profession' (GMC 2013b). This obligation also applies to medical students (GMC 2016) and development of professionalism is essential in medical curricula. Core principles outlined in the GMC's Good Medical Practice (2013b) include 
respecting patient confidentiality, avoiding expression of 'personal beliefs (including political, religious and moral beliefs) to patients in ways that exploit their vulnerability or are likely to cause them distress,' and challenging colleagues if they behave unprofessionally.

Discussions of medical professionalism point to the complex interweaving of practices and ideas in its development, 'running to and from various institutional policy documents, curricular documents, educational activities and academic literature which ultimately find their way into medical students' conceptualisations of professionalism through a dynamic process of resistance and negotiation’ (Monrouxe, Rees, and Hu 2011: 586). Further, influences abound in wider society, including as filtered through media treatment of medical professionalism.

\section{Challenges to medical professionalism through the growth of social media}

A significant aspect of this cultural background to the development of medical professionalism is the increased pervasiveness of social media. These are used for a variety of purposes in peoples' lives. Performance of identity through social media is a frequently observed phenomenon, as people project aspects of their interests and alignments and disalignment with social groups (Zappavigna 2014). Social media users construct apparent authenticity, while becoming skilled at strategically either addressing multiple audiences simultaneously, or separating them carefully through privacy controls (Georgalou 2016; Marwick and Boyd 2010). Continuity is achieved through the creation, often collaboratively with others, of "small stories". In professional domains, a growing range of studies have shown a diverse range of practices and motivations for self representation on social media, such as celebrities seeming to grant "backstage" access to their fans (Marwick and Boyd 2011). Even where social media is used with apparently instrumental reasons, such as Turkish mayors sharing information about public services they are nevertheless involved in 
self-promotion and communication of political messages (Sobaci and Karkin 2013). Social media is increasingly drawn on for formal and informal educational contexts (ee.g. Erstad 2013; Fenwick 2016; Gray, Annabell, and Kennedy 2010; Kind et al. 2014) and so the use of versatile platforms such as Facebook, Twitter, blogs and YouTube has blurred the boundaries between the personal and professional lives of medical practitioners and students.

Shore et al. (2011) identified four areas of ethical concern relating to the use of social media by health professionals: 'boundary issues in the patient-physician relationship, privacy and confidentiality, implications of the nature and scope of information available online, and physicians' self-presentation online' and these are echoed by others (Cheston, Flickinger, and Chisholm 2013; Chretien et al. 2010; MacDonald, Sohn and Ellis 2010; Thompson et al. 2008).

Owing to the relative recency of social media platforms, salient research regarding medical students’ practices is restricted to the last ten years. Within this time period there has been something of an evolution from work that reported matters of considerable concern to an increasingly positive recognition of the potential of social media. A few survey reviews have now been published also.

We first then discuss some individual studies which raised serious concerns. In 2008, Thompson et al. reported that $64.3 \%$ of the medical students at the University of Florida had Facebook accounts, of whom nearly two thirds had public profiles - viewable by all Facebook users. Similarly, MacDonald et al. (2010) found that $65 \%$ of recent medical graduates from the University of Otago had Facebook accounts, 37\% of which were publicly accessible. Closer examination of the public profiles in these studies revealed behaviour which may be considered unprofessional: evidence of excessive consumption of alcohol, violation of patient privacy and confidentiality, the use of potentially offensive language, 
nudity, illegal behaviour and association with groups which may have political, religious or offensive content. Political and religious views and sexual orientation were displayed on many of these profiles.

Cain, Scott and Akers (2009) surveyed students on entry to three pharmacy programmes in the United States on their use of and attitudes towards Facebook. Eighty eight per cent of students had a Facebook account, however only 55.3\% of students thought that they should be accountable for unprofessional behaviour on Facebook, with males significantly less likely to feel accountable. One third admitted to posting material which they would not want a patient to see; again this behaviour was reported more frequently by males. Kung, Eisenberg, and Slanetz (2012) surveyed radiology residents in the United States and found that $50 \%$ had witnessed unprofessional content on a social networking site and 8\% admitted to posting unprofessional material. Chretien et al. (2010), reporting on a focus group study of US medical students, described uncertainty around what was appropriate to post online and confusion relating to the boundary between personal and professional online identities.

Such studies have been joined by research which, fully cognizant of the difficulties and challenges presented by social media use, also focus on actual and potential benefits. There have been some valuable reviews synthesising individual studies. For example Cheston, Flickinger, and Chisholm (2013) reviewed fourteen studies of social media and medical education that met their inclusion criteria and found that use of social media was associated with improved knowledge and skills, and that it was particularly valuable in promoting learner engagement, feedback and collaboration. These were highlighted above challenges, however the latter included variable participation, technical difficulties, and, at a lower level, concerns with privacy and security. A review by Hamm et al. (2013) included ninety six studies, aiming to map current literature on the use of social media in health care, so moving beyond the educational context. Nevertheless, one of their main findings was that most 
research was concentred on the medical education context, in part presumably owing to the recognised importance of this issue.

In medical education then, the importance of teaching, assessing and modelling of digital professionalism has been increasingly recognised with an increase in recommendations for good practice (Ellaway 2010). For example Shore et al. (2011) recommended that students and healthcare personnel should have an awareness of expectations regarding confidentiality and privacy, use privacy settings, self-monitor their internet presence, maintain professional boundaries online, separate their personal and professional content and challenge or report others who post unprofessional content. Kind et al. (2014) adopt a more positive tone in their recommendations, arguing for the benefits of accessing information and participating in online communities. Their more cautionary notes could be summarised as urging students towards greater reflexivity in considering their processes of engagement and online identity construction. The breadth and depth of such ideas chime with advocates of a transformational approach to the development of professionalism in higher education, contrasted with a tick box approach to skills (Wilson et al. 2013). Guidance on the use of social media is now available then from a number of sources, including key institutions in the UK such the GMC (2013a) and the British Medical Association BMA (2011). In the USA meanwhile, we note that current guidance is greatly contested. The American Medical Association (AMA, 2013) suggests: 'To maintain appropriate professional boundaries physicians should consider separating personal and professional content online'. DeCamp, Koenig and Chisholm (2013: 581-2) identify this as a common recommendation in North American guidelines on social media use for medical practitioners but argue: " that this is operationally impossible, lacking in agreement among active physician social media users, inconsistent with the concept of professional identity, and potentially harmful to physicians and patients.” 


\section{Methods}

\section{Research context}

Against the background of increasing breadth and depth of research into digital professionalism, its opportunities and challenges, there opened up for us an opportunity to create a study that was local and interpretive, drawing on the ethos of an academic literacies approach (Lea and Street 1998; Paxton and Frith 2013). This perspective is underpinned by the belief that research needs to take account of how power and authority are experienced locally in relation to identity, understood as a constant work in progress. Thus communicative practices are contested and can conflict with one another, as diverse discourses are encountered at the local level. We aimed therefore to work at greater depth than a survey or interview methodology, allowing a small number of students an opportunity to voice and explore their own experiences and concerns in relative depth.

At the start of each academic year Lancaster University Medical students must sign a declaration stating that they have read and understood the documents on guidance on the use of social media by the GMC (2013a) and the BMA (2011). As discussed by Fenwick (2013, 2016) these documents tend to focus on prohibitions rather than recognise the positive opportunities in medical education related to use of social media. Nevertheless, the extent to which such guidance is followed and reflected in current digital professionalism practice is unknown.

\section{Research questions}

In order to investigate the students' awareness of the digital professionalism issues explained above, the following research questions were identified.

- How do these Lancaster University medical students use social media? 
- How do these medical students control and manage the projection of a professional identity in their social media practices?

- What awareness of unprofessional content do these medical students have, and what do they think about its implications?

\section{Data collection and participants}

The research questions are complex and multi-layered, and in order to elicit answers of sufficient depth and fullness, we used a focus group methodology. Focus groups are a wellestablished qualitative research method widely used in medical education and other health research (Kitzinger 1995; Krueger and Casey 2009; Stalmeijer, McNaughton, and Van Mook 2014). As Morgan (1996: 139) argued, drawing on medical sociology, "the real strength of focus groups is not simply in exploring what people have to say, but in providing insights into the sources of complex behaviors and motivations”. Focus groups depend a great deal upon their design and composition in order to generate in-depth discussion between participants in a safe environment where they are free to express views among their peers. However when they are successful, the group dynamics can mean that discussions can be richer than might otherwise be gained, e.g. through individual interviews (Gill, Stewart, Treasure and Chadwick 2008).

Following ethical approval granted by the Lancaster University Research Ethics Committee, eight participants were recruited to participate in the study from the Year 2 Medical degree (MBChB) course at Lancaster University on a voluntary basis. Six students attended a focus group (Litosseliti 2003). A qualitative checking mechanism was implemented through the conduct of a further paired interview of students from the same cohort. Participants were given a participant information sheet and the opportunity to ask questions about the project. All participants completed a consent form before commencement of the discussion. The eight students involved received a small compensation for their time. 
The focus group and paired interview were conducted according to a semi-structured interview template with questions relating to students' experiences and attitudes towards their own past, present and envisaged future behaviours with social media; that of others; opinions on actual and hypothetical dilemmas or problematic issues and elicited opinions on authentic social media postings by medical practitioners that were considered by the research team to be potentially problematic. A professional linguistic focus group facilitator and transcriber were employed, followed by a rigorous qualitative analysis procedure (Myers 1998). The second author attended the session, taking field notes.

We recognised the possibility that students might feel constrained to express their opinions in the context of the medical school in which the first author was situated. Therefore she was not involved in the recruitment, nor present during the data collection. She had no access to the data until after it was transcribed and anonymised. The students were invited to a location away from the medical school for the discussions. The facilitator and observer were not known to them. All these measures were undertaken in order to safeguard participants' confidential identities and mitigate any concerns that their contributions might affect the opinion held of them or impact on their standing within the medical school. As a brief comment on process, we would add that we found these measures worthwhile, in that the focus groups and interview were skilfully conducted; no one person dominated at any time. It appeared to the observer at the time that discussions were more reflective and fruitful in the focus group than the interview.

\section{Data analysis}

Each discussion was audio-recorded, transcribed verbatim and anonymised before analysis. The content of the discussions was analysed qualitatively, by taking a classic approach to focus group data analysis (Krueger and Casey 2009). Coding themes were created inductively from the data by each author first independently, then consensually, aiming at complete 
coverage of significant issues raised. The coding scheme created for the focus group was then applied to the data for the paired interview, which included seeking for any new categories. Analysis further considered such issues as the prevalence and degree of alignment of topics and the specificity of examples.

\section{Findings}

Analysis of the focus group transcript identified 22 codes. First it is important to state that the paired interview data did not lead to the creation of any additional codes. This both provided a warranty for the quality of the primary dataset and allowed for the discussion of the results together, so these are not distinguished forthwith. Analysis draws findings together under the substantive research questions.

It should be noted as an important preliminary finding that two topics occurred throughout: concern for the welfare of patients and a sense of digital practices as being entwined with physical world experiences, rather than conceived of as a realm apart.

\section{How do medical students use online social media?}

A basic finding was a commonality in preference among social media platforms. All students used Facebook and all but one used YouTube. They had experimented with Twitter but the majority did not regularly use it - as one said, they 'didn'treally understand how it all worked... what you're supposed to say.' However, they were aware that the medical student society, MedSoc, used Twitter to promote social events. Only two students mentioned Instagram and one student spoke of blogging, but these were insignificant either for social networking or gaining professional information.

Facebook provided a shared focus for experience. It was primarily considered a social tool, being used daily, mainly for sending messages and commenting on, rather than posting, status 
updates. This earlier studies, such as Madge et al. (2009) which found that Web 2.0 applications (e.g.social media) were rooted within daily routines, especially for young people and undergraduates to whom Facebook was, 'integral to student life.' Students declared they were less likely to add people as friends on Facebook than they had been in their school days.

Students used Facebook groups with those in their Problem Based Learning (PBL) groups to share resources, ask and answer questions and to organise activities. There was also some awareness of Facebook pages and groups designed for medical students more broadly.

Although ceasing using Facebook was a possibility for two students, this was equated with a sense of loss: '[Facebook is] the way that people contact each other so if you don't have it you really are kind of in the blue.'

Use of YouTube was relatively uniform: it was used as supportive for learning through watching lectures and practical skills demonstrations. Students did not upload their own material or discuss other interactive uses.

\section{How do medical students control and manage the projection of a professional identity in their social networking practices?}

There was considerable uncertainty about what was considered professional versus unprofessional both online and in the physical world:

'[Professionalism] is so hard to define you can't say this is the... definition of professionalism because so many different people could put so many different attributes into it...'

Students all considered that they had altered their behaviour as their sense of professional identity developed. They recognised that expectations of behaving professionally in clinical placements extended into personal domains including social media. 
'You wouldn't be professional in a GP [placement] and not be on Facebook... it's an allround thing'

However, the expected extent of professionalism in their social life was not clear to them in every area. Concern was expressed about friends tagging them in possibly inappropriate online pictures. Whilst one student reviewed tagged photos, others felt they did not have the time to do so. Privacy settings were used by the students, although there was confusion over what people who are not friends can see. So the avoidance of posting anything which might be considered even slightly unprofessional was a common strategy:

'Before I started you know I might have the odd status where you're whinging about your day or something I wouldn't do that now erm even if it isn't related to medicine I still think it kind of portrays you in a negative way.'

They attributed these changes to becoming medical students per se, rather than as a consequence of specific teaching sessions, or being required to sign an agreement to follow the GMC (2013a) and BMA (BMA, 2011) guidance on using social media.

Students were also asked to consider the contended policy statement extract by the American Medical Association (AMA, 2013) as discussed above: 'To maintain appropriate professional boundaries physicians should consider separating personal and professional content online'. Initially two students reacted by saying that they used social media for personal content only. However another pointed out that in fact they were already using Facebook for PBL groups, so for professional purposes. It was agreed that a separation of identities was not feasible, echoing the contention by DeCamp, Koenig, and Chisolm (2013) that social media platforms and indeed search engines make this unoperationalisable and indeed undesirable (given the concealment of identity that would have to be attempted) . 
Nevertheless, these students highlighted some differences between communicating online and in the physical world, suggesting for example that expression of humour is more risky online in comparison to a face-to-face encounter with patients. Students agreed that they did not envisage having patients as 'friends' on Facebook, although there was some awareness that existing Facebook friends may work in the health sector, or that patients might search for them on social media. However, they demonstrated naïveté around where they might encounter patients when going out in the evening, not realising that anyone can be a patient:

'... You wouldn't find patients necessarily in [a] lounge or a nightclub.'

Such dilemmas strongly resonated for them in terms of their developing professional identities and are therefore returned to below.

Overall, students were conscious of their transitional status, requiring the development of higher standards of professionalism and commensurate risks from consequences of any transgressions. The students envisaged their use of Facebook changing once practicing as a doctor, including unfriending people and removing content. Some also thought they might cease using Facebook after graduation, and thus delete their profiles.

'[I] personally don't see myself being like forty-year-old and having a Facebook page like you know I know people that do that but I don't I think it's more of a young person thing...'

Yet students did not suggest that the drivers for their Facebook use at present, both social and study-related, would cease. 


\section{What awareness do medical students have of actual and potential issues threatening professionalism, especially online, and what do they consider to be the implications?}

The students were acutely aware that patient confidentiality must be respected, both in the physical world and online. None had witnessed online comments about patients; yet unprofessional comments about tutors had been seen.

Aspects of life potentially related to perceptions of professionalism were elicited through the use of prompts and also drew some strong opinions. For example, the students were shown an anonymised Facebook post relating to American politics written by a doctor. They believed unanimously that doctors should be free to express such views, so long as these were not too extreme.

'Patients expect that their doctor's gonna have views on things like obviously they're gonna have opinions about political things.'

Expressing racism, homophobia and swearing, including on social media, were deemed wholly unacceptable. Some dubious activities specifically associated with social media were considered unprofessional, for example, 'fraping' the deliberate posting of inappropriate content on Facebook whilst logged into someone else's account (e.g. when they have left their phone or computer signed in). One student said she was on constant guard against this.

Students were shown various authentic examples of questionable material posted online and asked about their responses should they encounter such instances. Their responses depended not only on the degree to which they considered the content to be unprofessional, but also their relationship with the person posting. In regard to content they considered very mildly inappropriate, students declared that they would not post such comments, but neither would they challenge or report them. Some students would challenge close friends for minor infractions. They were, however, less likely to challenge a more senior student or doctor. 
Breaching confidentiality was seen as a serious offence to which students would generally be more inclined to respond to, regardless of the status of the offender, although even this could be expressed tentatively:

'If it was confidentiality things you might possibly say something.-'

The students' uncertainty around the boundary between their professional and personal lives was most apparent in relation to consuming alcohol:

'If [a doctor] were just like dancing and they were a bit drunk then I wouldn't care but if they were vomiting in the street then yeah I might care.'

They felt medical students in their age group are expected to drink alcohol, and that this had been reinforced by a recent BBC television programme 'Junior Doctors' (BBC Three, 2011). These students considered that alcohol consumption was not unprofessional in itself but that explicit drunkenness was inappropriate for them. This involved a delicate balancing act, involving matters of degree and audience:

'But it's a (very fine) line cause like if you're at like... a christening or a wedding and there's a photo with a glass of wine your hand and you're not drunk and you know it's a nice photo and you're with your family and stuff you would say that was acceptable but if it was like a bottle of Lambrini and you looked a bit like glazed...'

Concerns over the effects of alcohol use extended to an awareness that it might affect performance, and that if this was the case it could be unwise reflecting this in a selfdisclosing status update:

'Some people might post I don't know being hungover at a placement or something but I wouldn't consider that appropriate.' 
Smoking in public was considered less acceptable than drinking; however the students were all non-smokers. There were no situations, either in the physical world or online, where being publicly represented as smoking was seen as acceptable.

Participants believed that doctors should set an example or risk reducing adherence with medical advice.

\section{Conclusions}

\section{Medical students' use of online social media}

Facebook use was ubiquitous in our participants, although, in common with Chretien et al. (2010), some ambivalence was expressed. Ultimately it seemed to be considered necessary for social and learning-related reasons, reflecting research that has situated Facebook use 'within the “identity politics” of being a student' (Selwyn 2009: 157). As identified by others (Arteaga Sánchez, Cortijo, and Javed, 2014; Cheung, Chiu, and Lee, 2011)), social relations were identified as the major driver for use.

The students did not display awareness of themselves as part of a generation particularly associated with Facebook, contrasting recent studies reporting that younger generations associate it with people older than themselves (Miller 2013). Neither did they foresee their own continuing use of Facebook after graduation and commencement of their employment as a doctor, contrasting with published reports demonstrating use of Facebook by doctors and other healthcare professionals (Kung, Eisenberg and Slanetz 2012; MacDonald, Sohn and Ellis 2010; Ness, Sheehan and Snyder 2014; Osman, Wardle and Caesar 2012).

\section{Development of professional identity and awareness of challenges to professionalism}

Modifications in the use of Facebook were described by the students, reflecting their developing professional identity, both in relation to what they post and to whom they allow 
access. This reflects the portrayal of different 'acceptable identity fragments', as described by Kimmons and Veletsianos (2014), to varying audiences. Despite these changes, and as reported by Ross, Lai, Walton, Kirwan and White (2013), students struggled with the boundary between their professional and private lives, described by Finn, Garner and Sawdon (2010) as identity negotiation. Their discussion of alcohol illustrates this.

Alcohol. 'Alcohol consumption that affects clinical work or the work environment' is one of the most common reasons for reporting concerns to the GMC relating to medical students' fitness to practice include, along with 'breach of confidentiality' and 'sexual, racial or other forms of harassment' (GMC 2014), both of which were considered absolutely forbidden. In contrast, alcohol ingestion and its portrayal, challenged the students, who felt they were entitled to drink alcohol in their social life.

Numerous studies have examined UK medical student consumption of, and attitudes towards, alcohol (Ashton and Kamali 1995; Black and Monrouxe 2014; Granville-Chapman, Yu and White 2001; Newbury-Birch, White and Kamali 2000; Newbury-Birch, Walshaw and Kamali 2001; Pickard, Bates, Dorian, Greig and Saint 2000). A more recent cross-sectional study of medical students in the UK reported that $93.5 \%$ of medical students consumed alcohol, with $20.4 \%$ of those doing so with the aim of becoming inebriated most, or all of the time (Black and Monrouxe 2014). The great majority of informants had experienced great pressure to do so, during university activities such as (banned) initiation ceremonies, sports club events and birthday parties (Black and Monrouxe 2014).

However, Kimmons (2014) has pointed out that behaviour that might be considered appropriate in certain domains of private life - family celebrations, parties and so on, come to take on a particular tension if depicted on social media. This clearly connected with our students' concern over being depicted with alcohol on social media and a conclusion that a 
very finely drawn balance should be maintained. Social media platforms such as Facebook have an embedded set of values connected with the authentic projection of identity, so that participants conform to its norms and indeed receive more attention if they share images of such occasions, potentially including moderate depiction of alcohol. Mazer, Murphy and Simonds (2009) found that for teachers Facebook participation was more effective if they engaged in such self-disclosure. Yet Kimmons (2014: 97), reports several studies where such behaviour was sanctioned, even to the extent of persons losing their position 'for seemingly innocuous behaviours' displayed via social media. The students reflected some understanding of this dilemma, and, as reported by others (Chretien et al. 2010; Finn, Garner and Sawdon 2010), considered the potential sacrifices they may make for their career.

Social media guidance. Developments in their professional identity were attributed by students to simply 'being a medical student'. Influences of the curriculum, role models and signing a declaration agreeing to follow the GMC and BMA guidance on the use of social media are unclear in comparison to their conscious awareness of their changing sense of identity. Although of course the AMA (2013) guidelines are intended for a North American context rather than the UK, the students' stance would seem very much in support of the contestation of them by DeCamp, Koenig and Chisolm (2013). Those authors suggest it is salutary to remember that social media is essentially public.

Challenging and reporting unprofessional behaviour. Medical students and doctors are expected by the GMC (2013b) to challenge, or report, unprofessional behaviour. Reticence of doctors and other healthcare workers to raise concerns has been widely reported (BMA 2009; DesRoches et al. 2010; Hutchinson et al. 2001; Roland et al. 2011; White 2004), and this has received increased attention in the wake of the Mid Staffordshire NHS Foundation Trust scandal and publication of the Francis report which recommended the development of "greater candour throughout the system about matters of concern” (Francis 2013:4). Rennie 
and Crosby (2002) and Goldie et al. (2003) examined attitudes of medical students to raising concerns. Both studies suggested low proportions of medical students would report a concern; their decisions as to whether or not are founded on considerations as on harm to the patient and acting morally on the one hand and yet consequences for trust and friendship, fear of retaliation and self-preservation on the other.

The students in our study seemed unsure about whether they would challenge unprofessionalism online, and this related to the perceived severity of the unprofessional behaviour and the 'status' of the miscreant. This reflects the influence of hierarchy on medical student tendency to whistle-blow reported by Goldie et al. (2003). Student conceptions that they are not responsible for whistle-blowing concurs with the findings of Rennie and Crosby (2002) who reported a lack of perceived responsibility for raising concerns about academic misconduct. However, this contrasts with the GMC requirement to challenge or report unprofessional behaviour and has serious implications for clinical practice (GMC 2013b). Thus, there remains a role for additional education around whistle-blowing in undergraduate medical curricula.

\section{Limitations}

As with any study, there are potential limitations which must be considered when interpreting the results. The academic literacies approach, involving participation by a small number of people may uncover relatively rich details that aid the assistance of understanding of locally contested practices and their impact on identity but cannot simply be generalised more widely. Participants in this study were volunteers, and as such, were self-selecting - for example, all of the participants in this study were female. Sex differences have been previously reported in professionalism. Cain, Scott and Akers (2009) reported that males were less concerned with their online professionalism than females. Male medical students are also more likely to drink excessively (Keller et al. 2007; Newbury-Birch, White, and 
Kamali 2000; Newbury-Birch, Walshaw, and Kamali 2001). Thus the findings cannot be taken to apply across the medical student population as a whole

\section{Future research}

The results also raise many questions. These include: how will medical students alter their social media practices when they become doctors, and in particular how will they manage the boundary between their personal and professional lives? Does the likelihood of challenging or reporting unprofessional digital behaviour change as students progress through their medical training? Our research is limited to a snapshot in time and further research could usefully trace developments longitudinally in participants' practices, indeed as they move beyond undergraduate medical education. What, indeed, will be the practices and attitudes of this generation when they reach forty years' old? They are not likely to be identical to those of people who did not grow up with social media.

\section{Implications}

This study illustrates the reflections on early development by medical students of some aspects of their professional identity and related tensions across the online and physical world. It is also possible that some of our findings and discussion may have salience for other sectors, since dilemmas over self-presentation using social media exist for professionals such as teachers and lawyers (Ranieri, Manca and Fini 2012; Lackey Jr and Minta 2012).

For the present we have shown that variation in attitudes and practices in social media, uncertainty around where the boundaries lie between professional and unprofessional digital behaviour, and reticence to challenge unprofessional behaviour constitute challenges to medical education. These are not simple matters that can be addressed through approaches to medical ethics that focus on prohibitions rather than engaging with the complexities of navigating everyday life (Fenwick 2016; Stronach et al. 2002). Professional organisations 
involved in the production of guidelines and medical educators need to engage in more dialogue on these issues, as recommended by Wilson et al. (2013). While there is increasing recognition of the value of social media in medical education (Hamm et al. 2013) we would recommend that key institutions work with this new generation of students who are facing dilemmas that did not necessarily impact on their forebears in the same ways. Positive role modelling is also essential (Chretien and Kind 2014). As to the development of future policy, and how it is put into practice in medical education, we would concur with the recommendation of Kimmons (2014, 97) that "we must empower learners to participate in SNS [social networking services] in ways that are meaningful and truthful for them but that do not reduce identity to the strict confines of the medium.”

\section{References}

American Medical Association. 2013. AMA Code of Medical Ethics: Opinion 9.124 Professionalism in the Use of Social media. http://www.ama-assn.org/ama/pub/physicianresources/medical-ethics/code-medical-ethics/opinion9124.page. (Accessed January 2013).

Arteaga Sánchez, R., Cortijo, V., and Javed, U. 2014. Students' Perceptions of Facebook for academic purposes. Computers and Education, 70, 138-149.

Ashton, C.H., and Kamali, F. 1995. Personality, Lifestyles, Alcohol and Drug consumption in a sample of British medical students. Medical Education, 29(3), 187-192.

BBC Three. 2011-13. Junior Doctors: Your Life in Their Hands, Series 1, 2 and 3.

Black, L.F., and Monrouxe, L.V. 2014. 'Being sick a lot, often on each other': students' alcohol-related provocation. Medical Education, 48(3), 268-279. 
BMA (British Medical Association). 2009. Health Policy and Economic Research Unit. Speaking up for Patients, Final report. London: British Medical Association.

British Medical Association. 2011. Using Social media: practical and ethical guidance for doctors and medical students.

Cain, J., Scott, D., and Akers, P. 2009. Pharmacy Students’ Facebook Activity and Opinions Regarding Accountability and E-Professionalism. American Journal of Pharmaceutical Education, 73(6), 104.

Chandratilake, M., McAleer, S., Gibson, J., and Roff, S. 2010. Medical professionalism: what does the public think? Clinical Medicine, 10(4), 364-369.

Cheston, C., Flickinger, T., and Chisholm, M. 2013. Social media use in medical education: a systematic review. Academic Medicine, 88(6), 893-901.

Cheung, C. M. K., Chiu, P.-Y., and Lee, M. K. O. 2011. Online social networks: Why do students use Facebook? Computers in Human Behavior, 27(4), 1337-1343.

Chretien, K.C., Goldman, E.F., Beckman, L., and Kind, T. 2010. It's your own risk: medical students' perspectives on online professionalism. Academic Medicine, 85(10 Suppl), S68-71.

Chretien, K., and Kind, T. 2014. Climbing social media in medicine’s hierarchy of needs. Academic Medicine, 89(10), 1318-1320.

Cruess, S.R., Johnston, S., and Cruess, R.L. 2004. "Profession": A Working Definition for Medical Educators. Teaching and Learning in Medicine, 16(1), 74-76.

Dayter, D., 2015. Small stories and extended narratives on Twitter. Discourse, Context \& Media, 10, 19-26. 
DeCamp, M., Koenig, T.W. and Chisolm, M.S. 2013. Social Media and Physicians’ Online Identity Crisis. The Journal of the American Medical Association, 310(6), 581-582.

DesRoches, C., Rao, S., Fromson, J., Birnbaum, R., Iezzoni, L., Vogeli, C., and Campbell, E. 2010. Physicians' Perceptions, Preparedness for Reporting, and Experiences Related to Impaired and Incompetent Colleagues. Journal of the American Medical Association, 304(2), 187-193.

Ellaway, R. 2010. Digital professionalism. Medical Teacher, 32: 705-707.

Erstad, O. 2013. Digital Learning Lives: Trajectories, Literacies and Schooling. Peter Lang Publishing.

Fenwick, T. 2016. Social media, professionalism and higher education: a sociomaterial consideration. Studies in Higher Education, 41(4), 664-667.

Fenwick, T. (2014). Social media and medical professionalism: rethinking the debate and the way forward. Academic Medicine, 89(10), 1331-1334.

Finn, G., Garner, J., and Sawdon, M. 2010. 'You're judged all the time!' Students' views on professionalism: a multicentre study. Medical Education, 44(8), 814-825.

Francis, R. 2013. Report of the Mid Staffordshire NHS Foundation Trust Public Inquiry. London: The Stationery Office.

Gill, P., Stewart, K., Treasure, E., and Chadwick, B., 2008. Methods of data collection in qualitative research: interviews and focus groups. British Dental Journal (204), 291-295.

GMC (General Medical Council). 2016. Achieving good medical practice: guidance for medical students. http://www.gmc- 
uk.org/Achieving_good_medical_practice_0816.pdf_66086678.pdf. (Accessed February 2016).

General Medical Council. 2013a. Doctors' use of social media. http://www.gmcuk.org/guidance/ethical_guidance/21186.asp. (Accessed May 2014).

General Medical Council. 2013b. Good medical practice. http://www.gmcuk.org/guidance/good_medical_practice.asp. (Accessed May 2014).

General Medical Council. 2014. Most frequent areas of concern relating to student fitness to practise. http://www.gmc-uk.org/education/undergraduate/26643.asp.(Accessed May 2016).

Georgalou, M., 2016. "I make the rules on my Wall”: Privacy and identity management practices on Facebook. Discourse \& Communication, 10(1), 40-64.

Goldie, J., Schwartz, L., McConnachie, A., and Morrison, J. 2003. Students' attitudes and potential behaviour with regard to whistle blowing as they pass through a modern medical curriculum. Medical Education, 37(4), 368-375.

Granville-Chapman, J.E., Yu, K., and White, P.D. 2001. A follow-up survey of alcohol consumption and knowledge in medical students. Alcohol Alcohol, 36(6), 540-543.

Gray, K., Annabell, L., and Kennedy, G. 2010. Medical students' use of Facebook to support learning: insights from four case studies. Medical Teacher, 32(12), 971-976.

Hamm, M., Chisholm, A., Shulhan, J., Milne, A., Scott, S. D., Klassen, T., and Hartling, L. 2013. Social media Use by Health Care Professionals and Trainees: A Scoping Review. Academic Medicine,88(9), 1376-83. 
Hutchinson, A., McIntosh, A., Williams, M., and Barbour, R.S. 2001. Senior health professional's perceptions of variations in medical practice: a qualitative and quantitative study. Medical Education, 35: 45-51.

Keller, S., Maddock, J.E., Laforge, R.G., Velicer, W.F., and Basler, H.D. 2007. Binge drinking and health behavior in medical students. Addictive Behaviors, 32(3), 505-515.

Kimmons, R. 2014. Social Networking Sites, Literacy, and the Authentic Identity Problem. TechTrends, 58(2), 93-98.

Kimmons, R., and Veletsianos, G. 2014. The fragmented educator 2.0: Social networking sites, acceptable identity fragments, and the identity constellation. Computers and Education, 72, 292-301.

Kind, T., Patel, P.D., Lie, D., and Chretien, K.C. 2014. Twelve tips for using social media as a medical educator. Medical Teacher, 36(4), 284-290.

Kitzinger, J. 1995. Qualitative research: Introducing focus groups. BMJ, 311(7000), 299-302.

Krueger, R.A., and Casey, M.A. 2009. Focus Groups. A Practical Guide for Applied Research. (4th ed.). Thousand Oaks, CA: Sage Publications.

Kung, J., Eisenberg, R., and Slanetz, P. 2012. Reflective Practice as a Tool to Teach Digital Professionalism. Academic Radiology, 19(11), 1408-1414.

Lackey Jr, M.E. and Minta, J.P., 2012. Lawyers and social media: the legal ethics of tweeting, facebooking and blogging. Touro Law Review, 28(1), 149-182.

Lea, M., and Street, B.V. 1998. Student writing in Higher Education: an academic literacies approach. Studies in Higher Education 23(2) 157-172.

Litosseliti, L., 2003. Using focus groups in research. London: Continuum. 
MacDonald, J., Sohn, S., and Ellis, P. 2010. Privacy, Professionalism and Facebook: a dilemma for young doctors. Medical Education, 44(8), 805-813.

Madge, C., Meek, J., Wellens, J., and Hooley, T. 2009 Facebook, social integration and informal learning at university: "It is more for socialising and talking to friends about work than for actually doing work”, Learning, Media and Technology, 34(2), 141-155.

Marwick, A. and Boyd, D., 2011. To see and be seen: Celebrity practice on Twitter. Convergence: The International Journal of Research into New Media Technologies, 17(2), 139-158.

Mazer, J., Murphy, R., and Simonds, C. 2009. The effects of teacher self-disclosure via Facebook on teacher credibility. Learning Media and Technology, 34,(2), 175-183.

Miller, D. 2013. Facebook's so uncool, but it's morphing into a different beast. (Report from the Global Social media Impact Study). http://theconversation.com/facebooks-so-uncool-butits-morphing-into-a-different-beast-21548. (Accessed May 2014).

Monrouxe, L., Rees, C., and Hu, W. 2011. Differences in medical students’ explicit discourses of professionalism: acting, representing, becoming. Medical Education, 45: 585602.

Morgan, D.L., 1996. Focus groups. Annual Review of Sociology, 22, 129-152.

Myers, G. 1998. Displaying opinions: topics and disagreement in focus groups. Language in Society, 27(1), 85-111.

Ness, G., Sheehan, A., and Snyder, M. 2014. Graduating student pharmacists' perspectives on e-professionalism and social media: Qualitative findings. Journal of the American Pharmacists Association, 54(2), 138-143. 
Newbury-Birch, D., Walshaw, D., and Kamali. F. 2001. Drink and drugs: from medical students to doctors. Drug and Alcohol Dependence, 64(3), 265-270.

Newbury-Birch, D., White, M., and Kamali, F. 2000. Factors influencing alcohol and illic it drug use amongst medical students. Drug and Alcohol Dependence, 59(2), 125-130.

Osman, A., Wardle, A., and Caesar, R. 2012. Online professionalism and Facebook-falling through the generation gap. Medical Teacher,34(8), e549-556.

Page, R., 2012. Stories and social media: identities and interaction. London: Routledge.

Paxton, M., and Frith, V. 2013. Implications of academic literacies research for knowledge making and curriculum design. Higher Education, 67(2), 171-182.

Pickard, M., Bates, L., Dorian, M., Greig, H., and Saint, D. 2000. Alcohol and drug use in second-year medical students at the University of Leeds. Medical Education, 34(2), 148-150.

Ranieri, M., Manca, S. and Fini, A., 2012. Why (and how) do teachers engage in social networks? An exploratory study of professional use of Facebook and its implications for lifelong learning. British Journal of Educational Technology, 43(5), 754-769.

Rennie, S.C., and Crosby, J.R. 2002. Students' perceptions of whistle blowing: implications for self-regulation. A questionnaire and focus group survey. Medical Education, 36(2), 173179.

Roland, M., Rao, S., Sibbald, B., Hann, M., Harrison, S., Walter, A., Guthrie, B., DesRoches, C., Ferris, T.G., and Campbell, E. 2011. Professional values and reported behaviours of doctors in the USA and UK: quantitative survey. BMJ Quality and Safety Health Care, 20(6), 515-521. 
Ross, S., Lai, K., Walton, J.M., Kirwan, P., and White, J.S. 2013. "I have the right to a private life": medical students' views about professionalism in a digital world. Medical Teacher, 35(10), 826-831.

Selwyn, N. 2009. Faceworking: exploring students’ education-related use of Facebook. Learning Media and Technology, 34(2), 157-174.

Shore, R., Halsey, J., Shah, K., Crigger, B.J., and Douglas, S. 2011. Report of the AMA Council on Ethical and Judicial Affaris: Professionalism in the Use of Social media. Journal of Clinical Ethics, 22(2), 165-172.

Stalmeijer, R.E., McNaughton, N., and Van Mook, W.N. 2014. Using focus groups in medical education research: AMEE Guide No. 91. Medical Teacher, 36(11), 923-939.

Sobaci, M.Z. and Karkin, N., 2013. The use of twitter by mayors in Turkey: Tweets for better public services? Government Information Quarterly, 30(4), 417-425.

Stronach, I., Corbin, B., McNamara, O., Stark, S., and Warne, T. 2002. Towards an uncertain politics of professionalism: teacher and nurse identities in flux. Journal of Education Policy, 17(1), 109-138.

Thompson, L.A., Dawson, K., Ferdig, R., Black, E.W., Boyer, J., Coutts, J., and Black, N.P. 2008. The intersection of online social networking with medical professionalism. Journal of General Internal Medicine, 23(7), 954-957.

White, C. 2004. Doctors mistrust systems for reporting medical mistakes. BMJ, 329(7456), e12. 
Wilson, A., Åkerlind, G., Walsh, B., Stevens, B., Turner, B., and Shield, A. (2013). Making "professionalism" meaningful to students in higher education. Studies in Higher Education 38(8) 1222-1238.

Zappavigna, M., 2014. Enacting identity in microblogging through ambient affiliation. Discourse \& Communication, 8(2), 209-228. 